\title{
Influence of storage time on the quality and combustion behaviour of pine woodchips
}

M.D. Casal, M.V. Gil, C. Pevida, F. Rubiera ${ }^{*}$, J.J. Pis

Instituto Nacional del Carbon (C.S.I.C.). Apartado 73. 33080 Oviedo. Spain

\begin{abstract}
The current situation in the energy sector suggests the possibility of using biomass in co-combustion systems as an alternative to other fuels. In the case of the North of Spain the amount of forest residues that is generated guarantees it as a valuable source of energy for the future. However, an effective exploitation of these residues must first overcome a number of serious problems such as transport, storage, handling and pretreatment, to meet the requirements of the power plants. The aim of this work is to study the influence of storage time on the moisture content and chemical and combustibility properties of pine woodchips. Their combustibility behaviour was evaluated by means of the following tests: heating value, ash composition, slagging/fouling indices, and the combustion profiles obtained from TG analysis. As a result of the weather conditions in the North of Spain open air storage in the area under study is not suitable for dry pine woodchips, although their combustion behaviour remains practically unaltered.
\end{abstract}

Keywords: Storage time; Biomass; Combustion behaviour

\footnotetext{
* Corresponding author. Tel.: +34 985118 975; Fax: +34 985297662.

E-mail address: frubiera@incar.csic.es (Fernando Rubiera)
} 


\section{Introduction}

Biomass can be defined as any organic matter of recent origin that is derived from animals and vegetables as result of the photosynthesis. The term can include wood from a plant forest, residues from agricultural and forest production, and organic waste from industry, humans and animals. Currently, biomass is the third largest primary energy resource in the world after coal and oil [1]. With the worldwide increase in energy demand, the variability in the price of fossil fuels, and the concern about greenhouse gas emissions, biomass is an alternative energy source that could be used as a partial substitute for fossil fuels. The energy production from biomass represents an important part of the energy plan based on renewable resources promoted by European Union [2]. Biomass acts as a carbon sink while it is growing, and it is considered a carbon-neutral fuel, since the carbon dioxide released during the utilisation of the biomass remains an integral part of the carbon cycle. This means that the use of bio-energy, instead of fossil fuels, may help slow down global warming and minimise air pollution [3]. While biomass can be used directly (mostly in wood fires), it can be converted to higher forms of fuel. Several biomass utilisation technologies have reached a high degree of development during the last few decades, such as combustion, pyrolysis, gasification, liquefaction and biochemistry technology [3-6].

For biomass co-combustion in coal power plants it is necessary, among other things, to develop and improve the different stages of the logistics chain -transport, storage, handling and pre-treatment- in order to meet the requirements of the plant. Compared to more traditional energy transport technologies like electricity and gas, however, fewer efforts have so far been apparent in techno-economic modeling and optimization of biomass supply chains [7]. 
Material storage is one of the most difficult tasks when using biomass to produce energy. The drying of woodchips is a long process that requires large storage areas and usually results in transportation and storage costs that can be relatively significant [8]. The biomass must be stored in such a way that it is kept in good condition and, above all, protected from moisture.

Various research works have been carried out on the storage of biomass and related problems [9-13]. Some of them deal with the effects of particle size and pile height [9], others focus on spontaneous combustion due to biological activity [12], while others deal with the behaviour of different raw materials during storage [13]. From these studies it can be concluded that many factors play a role in the storage process.

The goal of this study is to optimise the exploitation of autochthonous resources of the North of Spain as a way to support the national energy industry. The main objective has been to find a methodology that will allow forest residues to be used as fuel in a cocombustion plant. Thus, the influence that storage time has on the different combustion characteristics of woodchip pine was studied over a storage period of 12 months.

\section{Materials and methods}

\subsection{Pile building and sampling}

The biomass used in this work was pine in the form of woodchips with an average size of $35 \times 25 \times 5 \mathrm{~mm}$, that were used to build a pile with a volume of approximately $70 \mathrm{~m}^{3}$. The geometric shape of the pile would have to be such that it would allow access to the point of sampling, without affecting the conditions of storage. It was therefore decided to construct a pile with a pyramidal configuration, a height of $3 \mathrm{~m}$, a total length of 10.5 $\mathrm{m}$ and an angle of $45^{\circ}$ (Figure 1). 
Since it was not possible to collect a sample from the pile by means of a probe, sampling was carried out by making vertical cuts at the sides. A diagram of the pile with the cutting system used for sampling and the positions where the cuts were made is shown in Figure 2. The sampling points are presented in Figure 3.

During the 12-month storage period, four biomass samplings were conducted. The sample corresponding to month 0, i.e. the initial sample, was collected at different time intervals during the transport truck unloading process. Samples from the cuts in the pile were taken at storage times of 3, 6 and 12 months. The cuts $1 / 4 \mathrm{~L}$ and 3/4 $\mathrm{L}$ were made at the front of the pile, whereas the cut $1 / 2 \mathrm{~L}$ was made at the back.

The nomenclature chosen to designate the samples was PXYZ, where P stands for pine; $\mathrm{X}$ is the sampling period: 1-initial, 2-three months, 3-six months, and 4-twelve months; $\mathrm{Y}$ is the position along the length of the pile, using 1 for $1 / 4 \mathrm{~L}, 2$ for $1 / 2 \mathrm{~L}$ and 3 for $3 / 4$ $\mathrm{L}$ (Figure 2); $\mathrm{Z}$ is the position inside the cut of the pile, i.e., 1 is used for $\mathrm{D} / 4$ and $1 / 4 \mathrm{H}$ (Figure 3). As an example, the initial sample is denoted as P100, while the samples corresponding to the third month are denoted as P211, P212, P213 and P214.

\subsection{Measurement of pile temperature and weather conditions}

The temperature of the pile was measured at three different points by means of thermocouples, whose positions are shown in Figure 3. These measurements were made once a week. Weather data such as ambient temperature, relative moisture, wind speed and precipitation were collected from a metrological station throughout the whole storage period. 


\subsection{Sample analyses}

The biomass samples were brought to the laboratory in hermetic containers. The total moisture was determined in accordance with the ISO 589 standard test. In addition, chemical characterisation was carried out and the heating value of the biomass samples was also measured. The major and minor elements in the ashes were analysed using Xray fluorescence spectrometry (XRF) with a Siemens SRS3000 equipment. The ash fusibility test was carried out according to the ASTM D1857 standard test under oxidising conditions, and as a result four different temperatures were established: initial deformation temperature, softening temperature, hemispherical temperature, and fluid temperature.

\subsection{Evaluation of combustion behaviour}

Thermogravimetric analysis (TG) techniques have been widely used for the assessment of the combustion behaviour of fossil fuels [13-18]. A plot of the rate of mass loss against temperature, while a sample is burnt under an oxidising atmosphere is referred to as a combustion profile [19-20]. Combustion profiles are especially useful for evaluating the combustion characteristics of biomass samples stored for different periods of time, due to the detailed information that can be obtained from the initial point of mass loss right up to complete combustion. In the combustion profiles a sample mass of approximately $5 \mathrm{mg}$ was placed in the sample crucible of a thermobalance, Setaram TAG24, and the temperature was increased to $1000{ }^{\circ} \mathrm{C}$ at $15^{\circ} \mathrm{C} \mathrm{min}^{-1}$ in an air flow of $50 \mathrm{~mL} \mathrm{~min}^{-1}$. 


\section{Results and discussion}

\subsection{Weathering conditions and moisture content during the storage period}

Figure 4 shows the variation in ambient temperature, and the temperatures measured at three points of the pile during the storage period. The sampling times are also plotted on this graph. The highest temperatures were recorded in the upper part of the pile, at point T3, where temperatures higher than $50{ }^{\circ} \mathrm{C}$ were recorded during the summer. Temperatures in the centre of the pile (T2) were slightly lower, whereas the lowest values were obtained at point 1 (T1). The variations in temperature inside the pile with time are similar, and they also follow a trend similar to that of the ambient temperature. In the woodchip pile, the temperature values were very close to ambient temperatures during the first four months of storage, corresponding to winter and spring. Afterwards, in the summer a sudden rise in temperature inside the pile was recorded, this increase being around $20{ }^{\circ} \mathrm{C}$ higher than the ambient temperature. The increase in temperature for the 6 months of storage was more marked in the internal upper part of the pile (T3), than in the outer lower part (T1). From November, temperatures in the pile started to decline rapidly, dropping to values close to the ambient temperature of $15{ }^{\circ} \mathrm{C}$ between December and February.

The temperature increase inside the pile may have been influenced by the size of the biomass. The fine particle size of the woodchips can cause high compaction inside the pile, reducing permeability and preventing the dissipation of heat. The size of woodchip used was not sufficiently large to allow natural ventilation [9]. However, although no study of the metabolic activity inside the stored woodchip was carried out, the heat generated from the microbial activity may have contributed to an increase in temperature inside the pile [12, 21]. 
With regard to the precipitation data, it can be seen in Figure 5 that the pluviometry data were high and varied between 12 and $200 \mathrm{~mm}$ during the period under study. These values were lower during summer, corresponding to the 6 months samples. Moisture content depends on the temperature and humidity of the environment, and the total moisture content of the initial sample P100 was found to be about $38.5 \%$ lower than the moisture in the other samples (Table 1). Differences in the total moisture content at various points in the pile, measured over the same storage period, are similar except for the samples taken during the third month of storage. In this case, the moisture in the samples from the outside of the pile (P211 and P214) was found to be higher than the moisture of the samples on the inside (P212 and P213), which display values very similar to those of sample P100.

On the other hand, the total moisture content of the six-month samples did not undergo any decrease, despite the higher temperatures and lower precipitations during this period, and they remained at about 55\%. In general, the moisture content increased with storage time and so the 12 month samples were considerably wetter, displaying a total moisture content of $70 \%$.

From these results it can be seen that total moisture increased from the outside to the inside of the pile, and also with storage time. An effective drying system during storage must ensure that woodchips are well exposed to the wind and the sun and that the air flows throughout the material. However, under the conditions of ambient temperature and high precipitation during the period under study (Figure 5), the woodchips did not experience any effective drying, as the relatively small particle size caused compaction of the biomass and reduced the flow of air through the pile. 


\subsection{Effect of storage time on proximate and ultimate analyses and heating values}

The proximate and ultimate analyses of the different samples, as well as their heating values are presented in Table 1. Biomass has a high volatile matter content that does not suffer significant variation during the storage time. On the other hand, there is a small decrease in carbon content, as the amount of oxygen increases slightly, indicating that the biomass underwent a slight oxidation or degradation during the storage period, independently of the sampling point. The sulphur and nitrogen contents are very low, except for the samples stored for 3 months, and in this case the amount of nitrogen is higher than for other samples. The low heating value (LHV), expressed on a moisture free basis -MF-, experienced a slight decrease with storage time and, as the heating value is a direct function of the biomass composition [22], this decrease in LHV may be related to the decrease in carbon content already mentioned. The LHV, as received, AR, showed a marked reduction, as a consequence of the increase in moisture content with storage time. If a plant has been purpose built to use moist fuels, no technical problems will occur. However high moisture content will affect the overall feasibility of energy production and result in lower fuel efficiency.

\subsection{Mineral matter content and ash fusibility tests}

Ash content is a convenient and widely used term which quantifies the solid residue that remains after a fuel has been burned under certain specific conditions. Generally, the ash content of biomass is low and, in the case of these samples, varies between 0.5 and $2 \%$ (Table 1). Biomass contains both organically-bound inorganic elements and mineral matter which result in the formation of ash during combustion. The inorganic element content of the ashes, usually expressed as oxides is shown in Table 2. The main 
component of the mineral matter is $\mathrm{SiO}_{2}$ (quartz), with values ranging between 50 and 60\%. Although $\mathrm{SiO}_{2}$ makes up a large amount of the ash content, calcium is also an important component of the biomass ash. The calcium oxide $(\mathrm{CaO})$ values lie between 5 and $13 \%$. The amount of aluminum expressed as $\mathrm{Al}_{2} \mathrm{O}_{3}$, is also significant, with data ranging between 5 and 22\%. It also needs to be borne in mind that from the point of view of chemical composition the biomass ash includes about $80 \%$ of $\mathrm{Si}$, $\mathrm{Ca}$ and $\mathrm{Al}$.

Table 2 shows that at the sampling point, the composition of the ashes is quite similar. The only important difference is the amount of $\mathrm{SiO}_{2}$, which is lower for the P422 and P423 samples, located in the interior of the pile, than for P421 and P424 which are taken from the outer part of the pile.

Depending on the time of storage, it can be seen that the ashes from the samples which were stored for 12 months (P421 to P424) are quite similar to one another. However, there are substantial differences between the ashes of the initial sample, P100, and the ashes from the samples which were stored for a year. The results presented in Table 2 indicate that storage time has affected the elemental composition of the ashes, this is most posibly due to the precipitations that have occurred during the long storage period underwent by the woodchips. Rain water may have dissolved elements of the water soluble form, which are primarily soluble salts such as alkali chlorides [23, 24].

Since ash fusibility is traditionally used to predict slagging and deposition during combustion, the melting temperatures were measured and are compared in Table 3. The approach followed in this study was adapted from a previously developed coal scheme for slagging/fouling formation mechanisms, and their influence in coal power plants [25]. Therefore, the results obtained for all the calculated indices, need to be interpreted bearing in mind the limitations of using this scheme for biomass fuels. 
The fusibility data shown in Table 3 indicate that the fusion temperatures of all the samples are quite high and similar to each other. These high temperatures reflect the high concentrations of biomass ashes in silicon and calcium along with their low alkali concentrations.

From the empirical slagging/fouling indices presented in Table 3, it can be concluded that the deposition tendency is low in accordance with the high values of the base-toacid ratio (B/A), resulting from the high concentrations of $\mathrm{SiO}_{2}$ and $\mathrm{Al}_{2} \mathrm{O}_{3}$. According to the slagging index, this tendency is medium due to the high hemispherical and initial deformation temperatures. In addition, the fouling propensity, evaluated from the sodium content, is low [25]. On the basis of these results, it can be concluded that storage time will not increase the slagging propensity of biomass ashes.

\subsection{Combustibility characteristics of the biomass samples}

The variations of mass loss with temperature for the biomass samples, stored for different periods of time, are shown in Figure 6. There is a striking similarity among all the samples, even though the mass loss was not affected by the different positions of the sampling points (1 to 4), but only by storage time. To better appreciate the differences between the samples, the DTG curves of the biomass woodchips stored during different periods of time, and sampled at point 3, are plotted in Figure 7. In addition, characteristic parameters extracted from the combustion profiles after the peak corresponding to loss of moisture, the maximum rate of mass loss (DTGmax), initial and final combustion temperatures (Ti and $\mathrm{Tf}$ ), and the temperature at the DTGmax, are shown in Table 4. 
The profile of the DTG curves is similar for all samples studied (Figure 7). The graphs indicate that the samples go through three stages during the combustion process. The first peak in the region $60-105{ }^{\circ} \mathrm{C}$ corresponds to the evolution of residual moisture of the air-dried samples. After a temperature range where mass loss is negligible, two distinct major peaks appear, corresponding to the combustion process. The peak between 150 and $340{ }^{\circ} \mathrm{C}$ is attributed to the evolution of volatile material, which in an oxidative environment (air), will ignite and burn. The heat generated is transferred to the whole mass of the sample and then the combustion of the residual char is initiated. This takes place in a temperature range between 340 and $500{ }^{\circ} \mathrm{C}$.

The temperature values at which the combustion peaks occur are useful data for evaluating the reactivity of the samples, the lowest Tmax values being indicative of more reactive fuels [19, 26]. It is observed that for storage times of 12 months, the peak temperatures, $\mathrm{Tmax}_{2}$, suffer a slight shift to lower values (Figure 7). In addition, deviations in the main peak heights also show that the samples differ in reactivity. The combustion profiles clearly show that the initial sample (P100) is the least reactive, and that combustion behaviour improves, the longer the period of storage. Furthermore, the combustibility characteristics of the biomass samples are affected by the storage time and not by their position in the pile. Samples from the same storage period but taken at different points in the pile did not show appreciable changes in their combustion behaviour, as can be seen in Table 4, which presents the maximum rates of mass loss, DTGmax, of the main peak. The slight increase in the maximum combustion rates of the samples with storage time can be attributed to the increase in oxygen content or in the degree of oxidation. 
Regardless of the sampling point, the initial temperature corresponding to the first region, $\mathrm{Ti}_{1}$, suffers a slight increase with storage time, while the final temperature of the main peak, $\mathrm{Tf}_{1}$, shifts to lower values from $366{ }^{\circ} \mathrm{C}$ for $\mathrm{P} 100$, to around $340{ }^{\circ} \mathrm{C}$ for the samples stored for 12 months (Table 4). This means that, as the period of storage increases, the time needed for the volatile matter to evolve and ignite decreases slightly. With regards to the third region the same tendency was found. In this case, samples stored for 12 months present a final temperature of combustion, $\mathrm{Tf}_{2}$, which is lower than that of the initial sample. This means that the total combustion of the samples is completed at a lower temperature with increasing storage time. Thus, it can be seen that after 12 months of storage, the samples are slightly more reactive. Nevertheless, between 3 and 12 months of storage there is no appreciable change in these parameters, and the changes detected in the DTG curves are very small.

\section{Conclusions}

During the 12 months that pine woodchips were stored under the climatic conditions typical of the North of Spain, it was observed that the moisture content of the pile increased with storage time. This indicates that, because of the weather conditions and the particle size of the woodchips, open air storage in the studied area is not an effective solution for dry biomass.

The characteristics of the biomass evaluated by means of heating value, ash composition, slagging/fouling indices, and the combustion profiles obtained from thermogravimetric analysis, indicate that the pile of woodchips underwent a slight deterioration with storage time, especially during the first three months of storage, remaining practically unaltered for longer periods of storage. The most important effect 
observed was a significant decrease in the heating value due to a marked increase in total moisture content with storage time.

\section{Acknowledgements}

Work carried out with financial support from the Spanish MICINN (Project PS-1200002006-3, ECOCOMBOS), and co-financed by the European Regional Development Fund, ERDF. The assistance from staff at La Pereda power plant owned by HUNOSA, is also gratefully acknowledged.

\section{References}

[1] Purohit P, Tripathi AK and Kandpal T CH Energetics of coal substitution by briquettes of agricultural residues. Energy. 2006; 31(8-9): 1321-1331

[2] Frombo F, Minciardi R, Robba M, Sacile R. A decision support system for planning biomass-based energy production. Energy 2009; 34:362-369.

[3] Baxter L. Biomass-coal co-combustion: opportunity for affordable renewable energy. Fuel. 2005; 84: 1295-1302.

[4] Di Blasi C. Modeling chemical and physical processes of wood and biomass pyrolysis. Progr Ener Comb Sci. 2008; 34 (1): 47-90.

[5] Solantausta Y, Beckman D, Bridgwater AV, Diebold JP and Elliott DC. Assessment of liquefaction and pyrolysis systems. Biomass Bioenerg. 1992; 2(1-6): 279-297.

[6] Caputo AC, Palumbo M, Pelagagge PM and Scacchia F. Economics of biomass energy utilization in combustion and gasification plants: effects of logistic variables. Biomass Bioenerg. 2005; 28:35-51.

[7] van Dyken S, Bakken BH, Skjelbred HI. Linear mixed-integer models for biomass supply chains with transport, storage and processing. Energy 2010; 35:1338-1350.

[8] Le Lostec B, Galanis N, Baribeault J, Millette J.Wood chip drying with an absorption heat pump.Energy 2008; 33:500-512.

[9] Jirjis R. Effects of particle size and pile height on storage and fuel quality of comminuted salix viminalis. Biomass Bioenerg. 2005; 28:193-201.

[10] Pettersson $M$ and Nordfjell T. Fuel quality changes during seasonal storage of compacted logging residues and young trees. Biomass Bioenerg. 2007; 31:782792.

[11] Nurmi J. The storage of logging residue for fuel. Biomass Bioenerg. 1999; 17: 4147.

[12] Buggeln R and Rynk R. Self-heating in yard trimmings: conditions leading to spontaneous combustion. Compost Science and Utilization. 2002; 10(2): 162-182. 
[13] White MS, Curtis ML, Sarles RL and Green DW. Effects of outside storage on the energy potencial of hardwood particulate fuels: part 1. Moisture content and temperature. Forest Prod J. 1983; 33(6): 31-38.

[14] Barkia H, Belkbir L and Jayaweera SAA. Oxidation kinetics of timahdit and tarfaya Moroccan oil shales. J Therm Anal Cal. 2003; 71: 97-106.

[15] Kök M V. Thermal analysis applications in fossil fuel science. Literature survey. J Therm Anal Cal. 2002; 68:1061-1077.

[16] Arenillas A, Rubiera F, Arias B, Pis JJ, Faúndez JM, Gordon AL and García XA. A TG/DTA study on the effect of coal blending on ignition behaviour. J Therm Anal Cal. 2004; 76: 603-614.

[17] Rubiera F, Arenillas A, Arias B, Pis JJ. Modification of combustion behaviour and NO emissions by coal blending, Fuel Process. Technol. 2002; 77:111-117.

[18] Pis JJ, de la Puente G, Fuente E, Morán A, Rubiera F. A study of the self-heating of fresh and oxidized coals by differential thermal analysis. Thermochim. Acta 1996; 279:93-101.

[19] Norton GA. A review of the derivative thermogravimetric technique (burning profile) for fuel combustion studies. Thermochim Acta. 1993; 214(2): 171-182.

[20] Rubiera F, Arenillas A, Pevida C, García R, Pis JJ, Steel KM, Patrick JW. Coal structure and reactivity changes induced by chemical demineralisation. Fuel Process. Technol. 2002; 79:273-279.

[21] Whihersaari M. Evaluation of greenhouse gas emission risk from storage of wood residue. Biomass Bioenerg. 2005; 28:444-453.

[22] Channiwala SA and Parikh PP. A unified correlation for estimating HHV of solid, liquid and gaseous fuels. Fuel. 2002; 81:1051-1063.

[23] Averlakis S, Gehrmann H, Beckmann M, Koukios EG. Agglomeration problems during fluidized bed gasification of olive-oil residue: evaluation of fractionation and leaching as pre-treatments. Fuel 2003; 82:1261-1270.

[24] Doshi V, Vuthaluru HB, Korbee R, Kiel JHA. Development of a modeling approach to predict ash formation during co-firing of coal and biomass. Fuel Process. Technol. 2009; 90:1148-1156.

[25] Couch G. Understanding slagging and fouling in PF combustion. IEA Coal Research; 1994.

[26] Rubiera F, Morán A, Martínez O, Fuente E, Pis JJ. Influence of biological desulphurisation on coal combustion performance. Fuel Process. Technol. 1997; 52:165-173. 


\section{Figure Captions}

Fig. 1. Dimensions of the pine woodchip pile.

Fig. 2. Prismatic pile and cutting system for sampling.

Fig. 3. Position of the sampling points and thermocouples in the pile.

Fig. 4. Ambient temperature and temperature profiles in the pile (T1, T2 and T3) during storage.

Fig. 5. Precipitation (mm) during the storage time.

Fig. 6. Variation of mass loss of the biomass samples.

Fig. 7. Evolution of combustion profiles of the biomass samples with storage time.

\section{Table Captions}

Table 1. Total moisture, proximate and ultimate analyses of the samples.

Table 2. Ash elements expressed as oxides of the samples stored for 0 and 12 months.

Table 3. Critical temperature points of the ash fusion test, and slagging/fouling indices for the samples stored for 0 and 12 months.

Table 4. Characteristic parameters of the biomass samples extracted from the combustion profiles. 


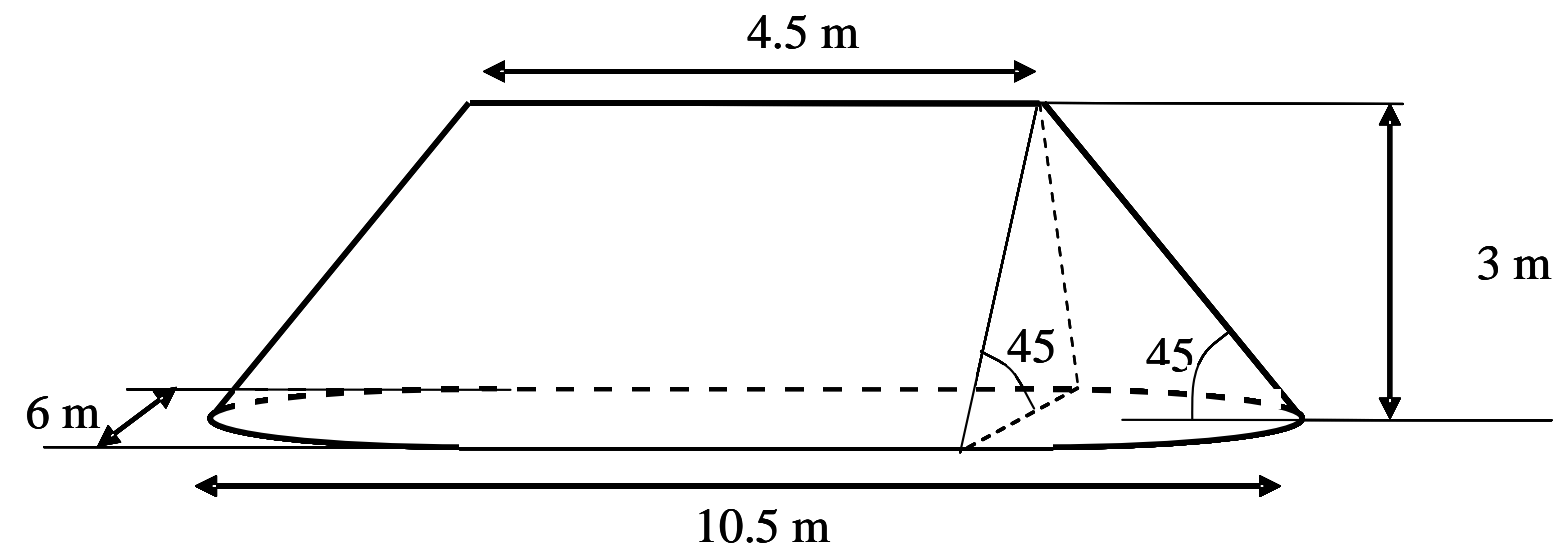

Fig. 1. Dimensions of the pine woodchip pile. 


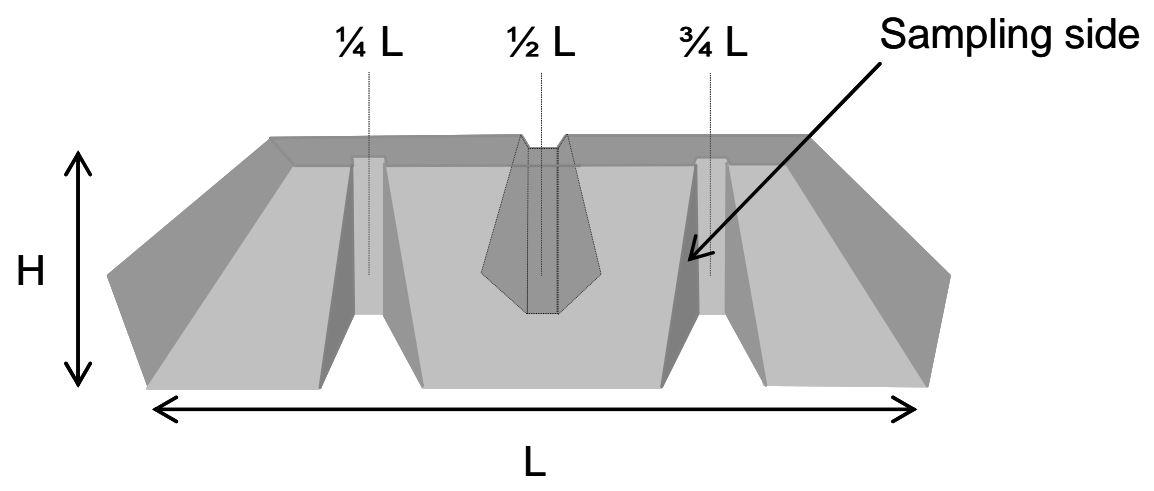

Fig. 2. Prismatic pile and cutting system for sampling. 


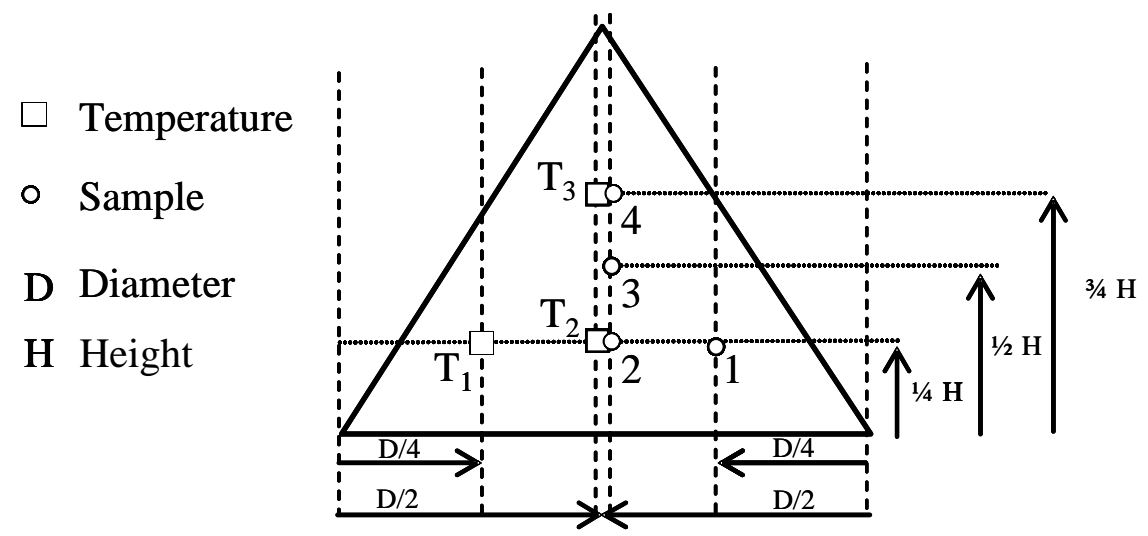

Fig. 3. Position of the sampling points and thermocouples in the pile. 


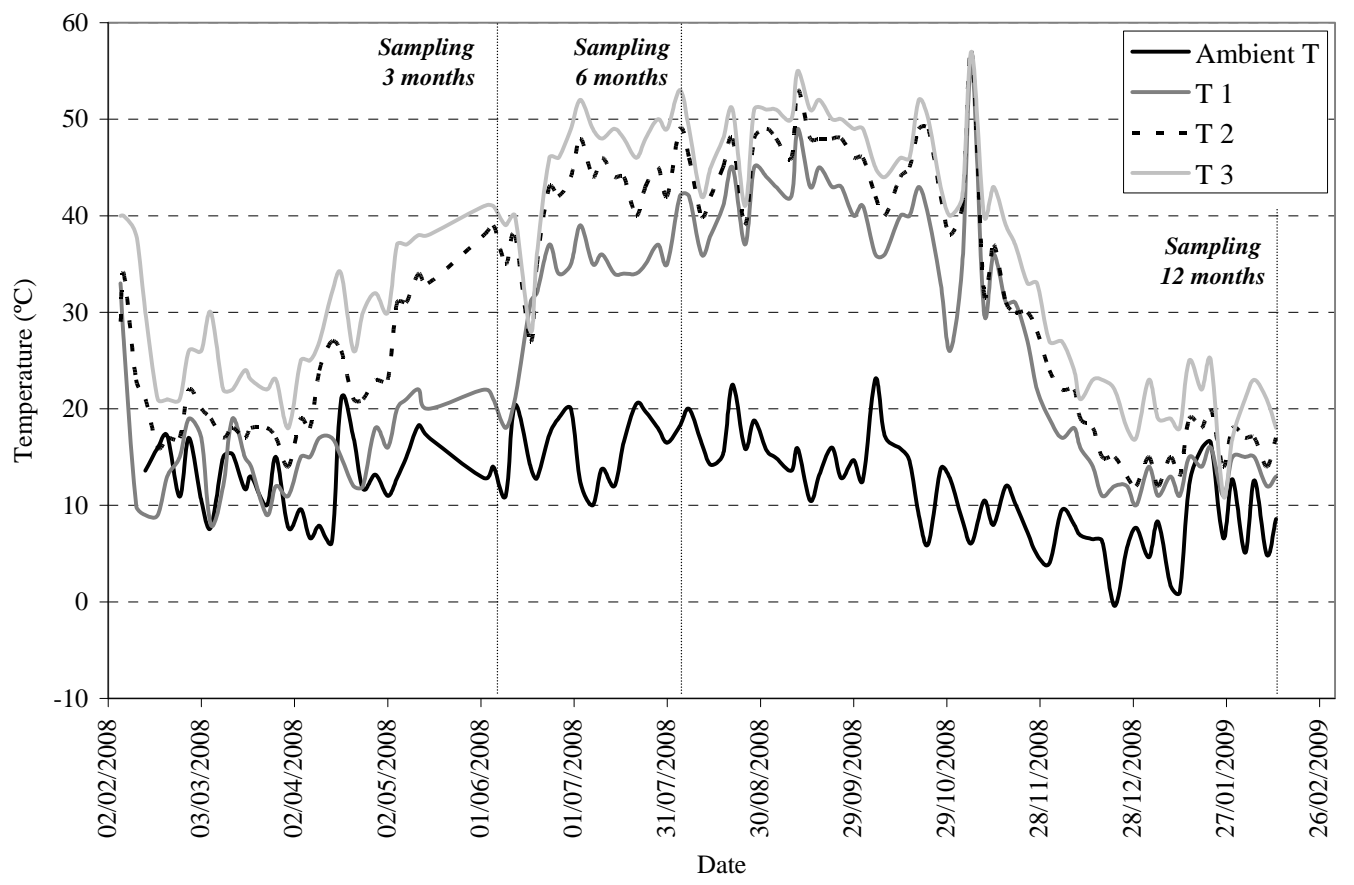

Fig. 4. Ambient temperature and temperature profiles in the pile (T1, T2 and T3) during storage. 


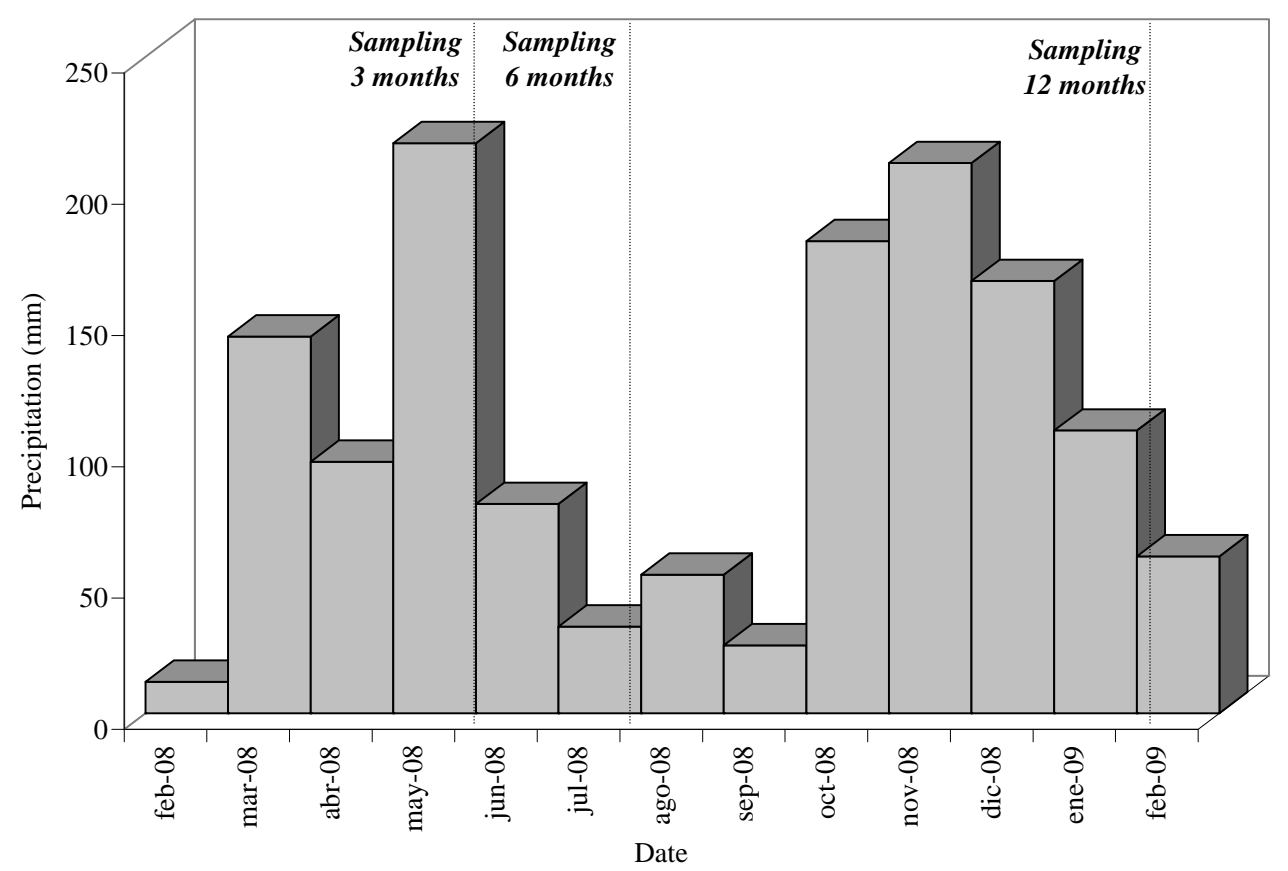

Fig. 5. Precipitation (mm) during the storage time. 


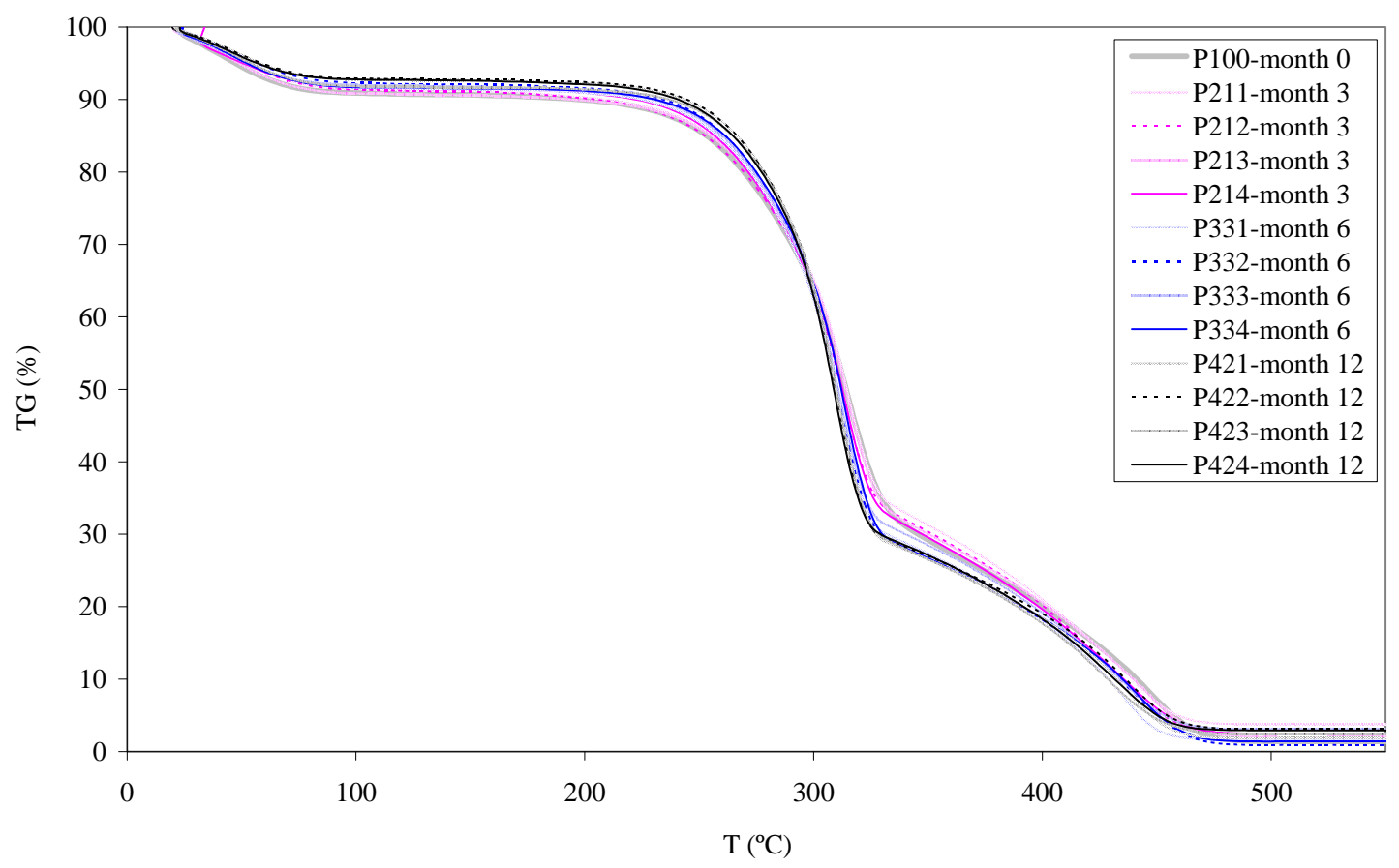

Fig. 6. Variation of mass loss of the biomass samples. 


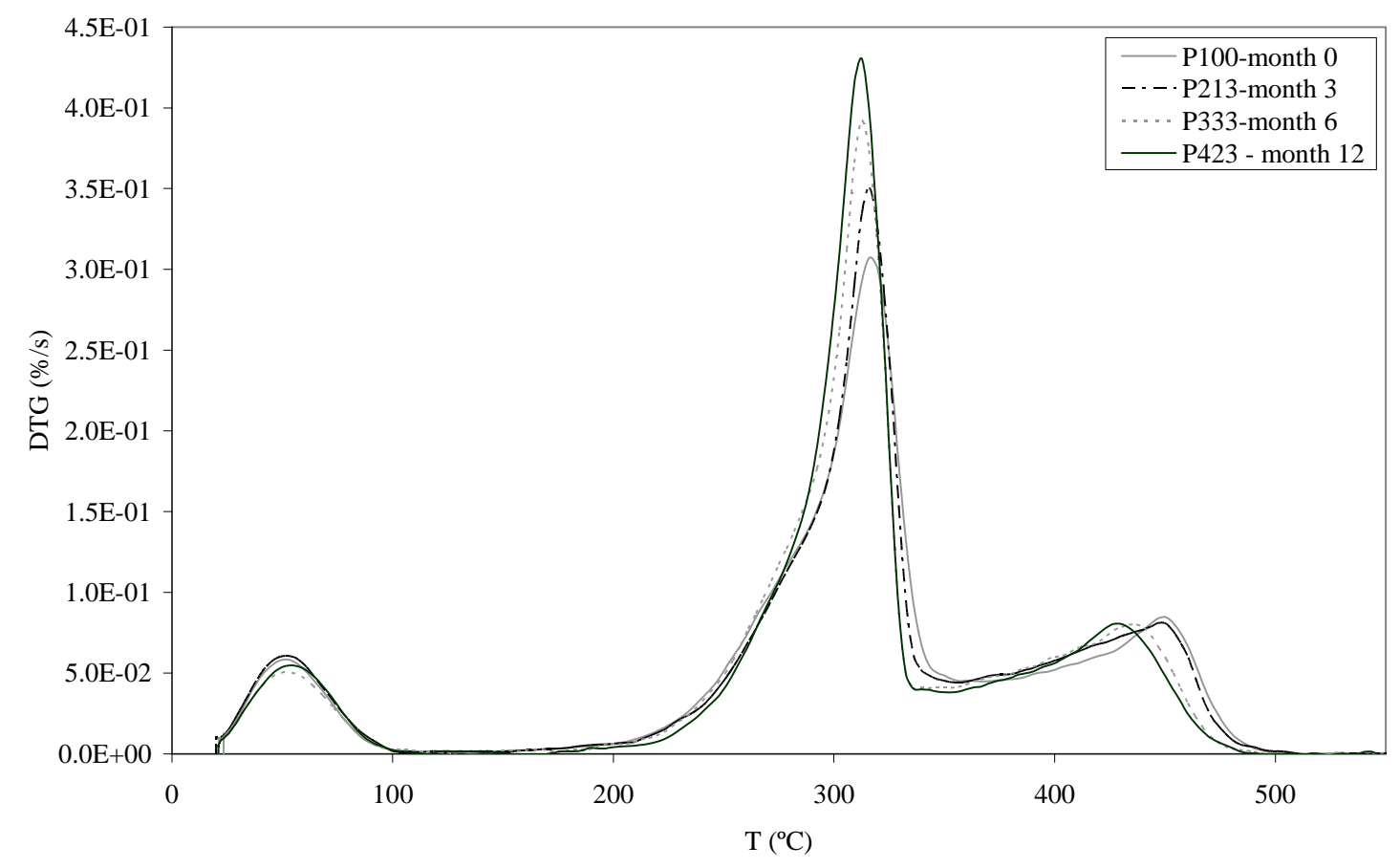

Fig. 7. Evolution of combustion profiles of the biomass samples with storage time. 
Table 1. Total moisture, proximate and ultimate analysis of the samples.

\begin{tabular}{|c|c|ccc|ccccc|cc|}
\hline & & \multicolumn{7}{|c|}{ Proximate analysis } & \multicolumn{5}{|c|}{ Ultimate analysis } & \multicolumn{3}{|c|}{ LHV } \\
\hline Sample & TM & Ash & VM & FC* & C & H & N & S & O* & MF & AR \\
\hline & $\%$ & \multicolumn{3}{|c|}{ db (\%) } & \multicolumn{7}{|c|}{ daf (\%) } \\
\hline P100- 0 month & 38.5 & 0.5 & 85.0 & 14.5 & 49.6 & 6.2 & 0.03 & 0 & 44.2 & 4503 & 2769 \\
\hline P211- 3 month & 63.2 & 2.3 & 79.6 & 18.1 & 50.5 & 5.9 & 0.3 & 0.02 & 43.3 & 4518 & 1663 \\
P212- 3 month & 38.1 & 1.9 & 78.9 & 19.2 & 50.5 & 6.0 & 0.4 & 0.03 & 43.1 & 4467 & 2763 \\
P213- 3 month & 47.8 & 1.8 & 79.1 & 19.1 & 50.3 & 5.7 & 0.3 & 0.05 & 43.7 & 4507 & 2353 \\
P214- 3 month & 65.1 & 1.8 & 80.0 & 18.2 & 51.2 & 5.9 & 0.3 & 0.03 & 42.6 & 4550 & 1588 \\
\hline P331- 6 month & 61.6 & 1.1 & 80.9 & 18.0 & 48.3 & 6.2 & 0.1 & 0.01 & 45.4 & 4443 & 1705 \\
P332- 6 month & 56.4 & 0.6 & 83.3 & 16.2 & 48.0 & 6.2 & 0.1 & 0.02 & 45.7 & 4421 & 1926 \\
P333- 6 month & 51.6 & 3.6 & 79.2 & 17.2 & 46.7 & 6.2 & 0.1 & 0.04 & 47.0 & 4251 & 2059 \\
P334- 6 month & 53.0 & 2.1 & 80.8 & 17.2 & 48.5 & 6.3 & 0.1 & 0.02 & 45.1 & 4344 & 2041 \\
\hline P421- 12 month & 71.6 & 1.3 & 82.9 & 15.8 & 47.6 & 6.1 & 0.1 & 0.01 & 46.2 & 4424 & 1259 \\
P422- 12 month & 70.3 & 1.8 & 82.2 & 16.0 & 47.0 & 6.0 & 0.1 & 0.03 & 46.9 & 4391 & 1303 \\
P423- 12 month & 68.1 & 2.1 & 83.2 & 14.7 & 45.5 & 6.2 & 0.1 & 0.04 & 48.2 & 4242 & 1354 \\
P424- 12 month & 69.2 & 1.9 & 82.3 & 15.9 & 46.6 & 6.1 & 0.2 & 0.03 & 47.1 & 4404 & 1356 \\
\hline
\end{tabular}

* Calculated by difference

TM: total moisture; VM: volatile matter; FC: fixed carbon; LHV : low heating value; db: dry basis; daf: dry and ash free bases; MF: moisture free; AR: as received 
Table 2. Ash elements expressed as oxides of the samples stored for 0 and 12 months.

\begin{tabular}{|l|c|cccc|}
\hline & P100 & P421 & P422 & P423 & P424 \\
\hline $\mathrm{SiO}_{2}(\%)$ & 61.24 & 59.75 & 53.11 & 52.46 & 58.03 \\
$\mathrm{Al}_{2} \mathrm{O}_{3}(\%)$ & 4.86 & 16.93 & 21.84 & 21.57 & 20.78 \\
$\mathrm{CaO}(\%)$ & 13.21 & 7.72 & 8.04 & 7.99 & 5.10 \\
$\mathrm{~K} 2 \mathrm{O}(\%)$ & 7.83 & 5.18 & 5.31 & 5.25 & 4.41 \\
$\mathrm{MgO}(\%)$ & 4.42 & 2.54 & 2.43 & 2.45 & 1.96 \\
$\mathrm{Fe}_{2} \mathrm{O}_{3}(\%)$ & 2.90 & 4.53 & 5.56 & 5.54 & 5.10 \\
$\mathrm{Na}_{2} \mathrm{O}(\%)$ & 1.51 & 0.67 & 0.71 & 0.71 & 0.55 \\
$\mathrm{P}_{2} \mathrm{O}_{5}(\%)$ & 1.41 & 0.52 & 0.48 & 0.48 & 0.34 \\
$\mathrm{TiO}_{2}(\%)$ & 0.30 & 0.65 & 0.81 & 0.80 & 0.80 \\
\hline
\end{tabular}


Table 3. Critical temperature points of the ash fusion test, and slagging/fouling indices for the samples stored for 0 and 12 months.

\begin{tabular}{|c|cccc|ccc|}
\hline & \multicolumn{3}{|c|}{ Critical temperature points $\left({ }^{\circ} \mathrm{C}\right)$} & \multicolumn{3}{c|}{ Slagging/Fouling indices } \\
\hline Sample & IT & ST & HT & FT & B/A & Slagging index & $\mathrm{Na}_{2} \mathrm{O}$ \\
\hline P100 & 1210 & 1228 & 1313 & 1373 & 0.4 & 1232 & 1.51 \\
\hline P421 & 1265 & 1285 & 1305 & 1375 & 0.3 & 1273 & 0.67 \\
P422 & 1285 & 1300 & 1315 & 1350 & 0.3 & 1291 & 0.71 \\
P423 & 1290 & 1310 & 1335 & 1350 & 0.3 & 1299 & 0.71 \\
P424 & 1290 & 1310 & 1335 & 1380 & 0.2 & 1299 & 0.55 \\
\hline
\end{tabular}

IT: initial deformation temperature; ST: softening temperature; HT: hemispherical temperature; FT: fluid temperature; Slagging index: (B/A). (Sulphur dry); B/A: baseacid ratio $=\left(\mathrm{Fe}_{2} \mathrm{O}_{3}+\mathrm{CaO}+\mathrm{MgO}+\mathrm{Na}_{2} \mathrm{O}+\mathrm{K}_{2} \mathrm{O}\right) /\left(\mathrm{SiO}_{2}+\mathrm{Al}_{2} \mathrm{O}_{3}+\mathrm{TiO}_{2}\right)$. 
Table 4. Characteristic parameters of the biomass samples extracted from the combustion profiles.

\begin{tabular}{|l|cccccc|}
\hline Sample & $\begin{array}{c}\mathrm{Ti}_{1} \\
\left({ }^{\circ} \mathrm{C}\right)\end{array}$ & $\begin{array}{c}\mathrm{Tf}_{1} \\
\left({ }^{\circ} \mathrm{C}\right)\end{array}$ & $\begin{array}{c}\mathrm{Tf}_{2} \\
\left({ }^{\circ} \mathrm{C}\right)\end{array}$ & $\begin{array}{c}\mathrm{Tmax}_{1} \\
\left({ }^{\circ} \mathrm{C}\right)\end{array}$ & $\begin{array}{c}\mathrm{Tmax}_{2} \\
\left({ }^{\circ} \mathrm{C}\right)\end{array}$ & $\begin{array}{c}\text { DTGmax } \\
(\% / \mathrm{s})\end{array}$ \\
\hline P100- & 212 & 366 & 484 & 316 & 450 & 0.307 \\
\hline P211- 3 & 210 & 343 & 474 & 316 & 443 & 0.351 \\
P212- 3 & 210 & 346 & 477 & 312 & 430 & 0.349 \\
P213- 3 & 215 & 350 & 480 & 315 & 449 & 0.350 \\
P214- 3 & 209 & 343 & 477 & 316 & 443 & 0.358 \\
\hline P331- 6 & 216 & 336 & 464 & 313 & 437 & 0.391 \\
P332- 6 & 216 & 339 & 477 & 312 & 443 & 0.394 \\
P333- 6 & 216 & 339 & 470 & 312 & 437 & 0.392 \\
P334- 6 & 220 & 343 & 477 & 314 & 443 & 0.405 \\
\hline P421- 12 & 220 & 336 & 470 & 312 & 440 & 0.439 \\
P422- 12 & 220 & 336 & 474 & 312 & 440 & 0.442 \\
P423- 12 & 223 & 339 & 470 & 312 & 435 & 0.431 \\
P424- 12 & 220 & 339 & 470 & 309 & 440 & 0.429 \\
\hline
\end{tabular}

$\mathrm{Ti}_{1}$ : initial Temperature of the second peak; $\mathrm{Tf}_{1}$ : final temperature of the second peak; $\mathrm{Tf}_{2}$ : final temperature of the third peak; $\operatorname{Tmax}_{1}$ : maximum temperature of the second peak; Tmax 2 : maximum temperature of the third peak. 